OPEN ACCESS

Edited by:

Fatma Mohamady El-Demerdash, Alexandria University, Egypt

Reviewed by: Tian Xia,

UCLA David Geffen School of Medicine, United States Masanori Horie, Adina Institute of Science and Technology (AIST), India

*Correspondence: Jae-Ho Oh mfdsnc@korea.kr Jong Kwon Lee jkleest@korea.kr

Specialty section: This article was submitted to

Predictive Toxicology, a section of the journal Frontiers in Pharmacology

Received: 10 November 2020 Accepted: 15 January 2021

Published: 19 February 2021

Citation: Kim S-H, Lee $J H$, Jung $K$, Yang $J$ - Y, Shin H-S, Lee JP, Jeong J, Oh J-H and Lee JK (2021) Copper and Cobalt lons

Released from Metal Oxide

Nanoparticles Trigger Skin Sensitization.

Front. Pharmacol. 12:627781. doi: 10.3389/fphar.2021.627781

\section{Copper and Cobalt Ions Released from Metal Oxide Nanoparticles Trigger Skin Sensitization}

\author{
Sung-Hyun Kim, Jin Hee Lee, Kikyung Jung, Jun-Young Yang, Hyo-Sook Shin, \\ Jeong Pyo Lee, Jayoung Jeong, Jae-Ho Oh* and Jong Kwon Lee*
}

Division of Toxicological Research, National Institute of Food and Drug Safety Evaluation, Ministry of Food and Drug Safety, Osong, South Korea

Human skins are exposed to nanomaterials in everyday life from various sources such as nanomaterial-containing cosmetics, air pollutions, and industrial nanomaterials. Nanomaterials comprising metal haptens raises concerns about the skin sensitization to nanomaterials. In this study, we evaluated the skin sensitization of nanomaterials comparing metal haptens in vivo and in vitro. We selected five metal oxide NPs, containing copper oxide, cobalt monoxide, cobalt oxide, nickel oxide, or titanium oxide, and two types of metal chlorides $\left(\mathrm{CoCl}_{2}\right.$ and $\left.\mathrm{CuCl}_{2}\right)$, to compare the skin sensitization abilities between NPs and the constituent metals. The materials were applied to KeratinoSens ${ }^{\mathrm{TM}}$ cells for imitated skin-environment setting, and luciferase induction and cytotoxicity were evaluated at $48 \mathrm{~h}$ post-incubation. In addition, the response of metal oxide NPs was confirmed in lymph node of BALB/C mice via an in vivo method. The results showed that $\mathrm{CuO}$ and $\mathrm{CoO}$ NPs induce a similar pattern of positive luciferase induction and cytotoxicity compared to the respective metal chlorides; $\mathrm{Co}_{3} \mathrm{O}_{4}, \mathrm{NiO}$, and $\mathrm{TiO}_{2}$ induced no such response. Collectively, the results implied fastdissolving metal oxide ( $\mathrm{CuO}$ and $\mathrm{CoO}$ ) NPs release their metal ion, inducing skin sensitization. However, further investigations are required to elucidate the mechanism underlying NP-induced skin sensitization. Based on ion chelation data, metal ion release was confirmed as the major "factor" for skin sensitization.

\footnotetext{
Keywords: skin sensitization, alternative test, KeratinoSens ${ }^{\mathrm{TM}}$, LLNA, dissolving nanoparticles, nanoparticles, copper, cobalt
}

\section{INTRODUCTION}

Metal oxide nanoparticles (NPs) constitute one of the major types of nanomaterials (NMs) that are used in industrial, biomedical, and cosmetic applications. With an increase in the number and production volume of NPs, concerns about their toxicity have increased exponentially in the recent years. While the major NP-exposure pathways include inhalation, ingestion, and absorption into the skin, the latter can cause lesions such as local inflammation, contact allergy, and skin sensitization (Oberdörster et al., 2005; Maynard and Kuempel, 2005). With an exponential increase in the commercialization of NPs in cosmetics and relevant safety concerns, evaluation of NP safety has become important (Katz et al., 2015). In recent cosmetic tests, the importance of alternative test methods considering animal welfare and the $3 \mathrm{R}$ principles has been emphasized (Rusche, 2003; Kaluzhny et al., 2011). However, since these guidelines are based on chemical substances, 
development of alternative test methods reflecting the properties of nanomaterials are also imperative.

The physicochemical properties of NPs form the key determinants of its toxic potential (Donaldson et al., 2013; Braakhuis et al., 2014). NPs, in most cases, are minimally soluble under normal physiological conditions; however, some have been shown to be soluble in certain media, such as lysosomal fluid (Cho et al., 2012; Cho et al., 2013). Dissolution of such NMs causes toxicity different from that caused by NMs that do not dissolve well, possibly due to the released ions. According to Cho et al., 2012, the toxicity of fast-dissolving metal oxide NPs is closely related to the intrinsic toxicity of its constituent metal ions.

Current knowledge regarding the chemical and biological mechanisms associated with skin sensitization has been summarized in the form of an adverse outcome pathway (starting with the molecular initiating event, through intermediate events, to the adverse effect), namely allergic contact dermatitis (OECD, 2018a). The first key event involves the initial covalent reaction of electrophilic chemicals in the irritant with nucleophilic thiol and primary amines in skin proteins. The second key event occurs within the keratinocytes and includes inflammatory responses as well as changes in gene expression associated with specific cell signaling pathways, such as the antioxidant/electrophile response element (ARE)dependent pathways (OECD, 2014). The ARE-Nrf2 Luciferase KeratinoSens $^{\mathrm{TM}}$ test, representing the second key event, can discriminate between skin sensitizers and non-sensitizers under the United Nations Globally Harmonized System of Classification and Labelling of Chemicals (OECD, 2018a).

Park et al., 2011, had reported titanium oxide NPs to not induce skin sensitization in mice, as per a local lymph node BrdUenzyme-linked immunosorbent assay. In contrast, gold NPs had been shown to bind non covalently to proteins and affect the immune system (Yoshioka et al., 2017). In addition, the NPs may release free chemicals with skin sensitization properties (Dwivedi et al., 2011; Dykman and Khlebtsov, 2017). However, there is still little information on the possible skin sensitization of NPs.

This study aimed to evaluate the skin sensitization potential of metal oxide NPs using the ARE-Nrf2 Luciferase KeratinoSens ${ }^{\text {TM }}$ assay and LLNA-FCM assay. In addition, the effect of release of ions from metal oxide NPs on skin sensitization were investigated in a dose-dependent manner.

\section{MATERIALS AND METHODS}

\section{NPs and Metal Chlorides}

$\mathrm{CoO}, \mathrm{Co}_{3} \mathrm{O}_{4}, \mathrm{CuO}$, and $\mathrm{TiO}_{2}$ NPs were purchased from Nanostructured and Amorphous Materials (Houston, TX, United States). NiO NPs were purchased from US-Nano (Houston, TX, United States). Metal chlorides $\left(\mathrm{CoCl}_{2}, \mathrm{CuCl}_{2}\right.$; Sigma-Aldrich, St Louis, MO, United States) were used for testing the constituent metal ions. Their primary size was confirmed by transmission electron microscopy (JEM-1200EX II, JEOL, Tokyo, Japan). The hydrodynamic size, polydispersity, and zeta potential of the NPs were measured using a Zetasizer Nano ZS instrument
(Malvern Instruments, Malvern, United Kingdom), in different vehicles, including distilled water (DW), Dulbecco's Modified Eagle's Medium (DMEM; GIBCO, Grand Island, NY, United States) containing $1 \%$ heat-inactivated fetal bovine serum (FBS; GIBCO) for KeratinoSens ${ }^{\mathrm{TM}}$ assay, and LLNA: BrdU-FCM assay working solution (DMF solution containing $3 \%$ mouse serum). The levels of endotoxin were evaluated using an Endpoint Chromogenic Limulus Amoebocyte Lysate assay (Cambrex Corporation, Walkersville, MD, United States).

\section{Metal Oxide NPs Dissolution Assay}

The dissolution of NPs was measured in artificial lysosomal fluid (ALF, pH 5.5) or phosphate buffered saline (PBS, pH 7.4), as previously described (Jeong et al., 2015, 2016). Briefly, NPs were dispersed in each medium at $100 \mu \mathrm{g} / \mathrm{ml}$ and incubated for $48 \mathrm{~h}$ at room temperature. Centrifugation was performed thrice at 15,000 $\times \mathrm{g}$ for $30 \mathrm{~min}$ to collect the NP-free supernatant, and absence of NPs was confirmed by dynamic light scattering (DLS) analysis using a Zetasizer Nano ZS (Malvern). Concentration of metal ions in the supernatant was measured using inductively coupled plasma optical emission spectroscopy (ICP-OES; 700-ES, Varian Inc., United States). Solubility was calculated as the percentage of dissolved metal concentration regarding the initial mass of metal in the NP suspension.

\section{Cell Culture and Treatment of KeratinoSens $^{\mathrm{TM}}$ with NPs}

A transgenic cell line with stable insertion of the luciferase reporter gene under the control of ARE-element KeratinoSens $^{\text {TM }}$ was obtained from Givaudan Suisse SA (Vernier, Switzerland). The cells were cultured in DMEM supplemented with $10 \%$ FBS and $0.5 \mathrm{mg} / \mathrm{ml}$ Geneticin (G418; Sigma-Aldrich). KeratinoSens ${ }^{\mathrm{TM}}$ cells were sub-cultured every 3-4 days at $80-90 \%$ confluence for a maximum of 25 passages. For the experiments, KeratinoSens ${ }^{\mathrm{TM}}$ cells were seeded into 96well plates at a density of $1 \times 10^{4}$ cells/well, the medium was replaced with fresh medium (DMEM supplemented with $1 \%$ FBS), and eventually incubated in a humidified atmosphere of $5 \%$ $\mathrm{CO}_{2}$ at $37^{\circ} \mathrm{C}$.

The NP suspensions in media were prepared by modifying the previously described method (Jeong et al., 2018). Briefly, the NP stock solution was dispersed in DW at a concentration of $200 \mathrm{mM}$ and sonicated at $40 \mathrm{kHz}$ with $100 \mathrm{~W}$ output power for $10 \mathrm{~min}$ in a bath-type sonicator (Saehan-Sonic, Seoul, South Korea). Then, DMEM supplemented with 1\% FBS was added to different working concentrations $(0.98-2000 \mu \mathrm{M})$. Then KeratinoSens ${ }^{\mathrm{TM}}$ cells were treated with NPs from a concentration of $2000 \mu \mathrm{M}$ to serial dilution. Since $\mathrm{CoO}$ and $\mathrm{Co}_{3} \mathrm{O}_{4} \mathrm{NPs}$ have the same constituent elements, the ion concentration was calculated for comparison and treated as the constituent element ratio. If metal chloride occurs, each cell was treated by converting the ion concentration to the constituent element ratio.

\section{Luciferase Induction and Cytotoxicity Assay} To assess the induction of luciferase activity in KeratinoSens ${ }^{\mathrm{TM}}$ cells, the latter were seeded into 96-well plates at a density of 
$1 \times 10^{4}$ cells/well and incubated overnight to approximately $80 \%$ confluence. The cells were washed thrice with pre-warmed DPBS (Gibco) followed by adding fresh medium containing test materials $(0.98-2000 \mu \mathrm{M})$ and incubation for $48 \mathrm{~h}$. Luciferase activity was measured using the ONE-Glo ${ }^{\mathrm{TM}}$ luciferase assay kit (Promega). Luminescence intensity of each sample was measured using a luminometer (Promega) and multi-microplate reader (Synergy 2, BioTek, Winooski, VT, United States). Luciferase induction was calculated based on the luminescence values of the vehicle control and blank.

For cell viability test, briefly, KeratinoSens ${ }^{\mathrm{TM}}$ cells were seeded into 96-well plates at a density of $1 \times 10^{4}$ cells/well and incubated overnight to reach approximately $80 \%$ confluence. The cells were washed once with pre-warmed DPBS (Gibco), followed by adding fresh medium containing test materials $(0.98-2000 \mu \mathrm{M})$ and incubation for $48 \mathrm{~h}$. Cell viability was measured by a thiazolyl blue tetrazolium bromide (3-(4,5-dimethylthiazol-2-yl)-2,5diphenyl-tetrazolium bromide) assay (Promega, Madison, WI, United States). To exclude colorimetric interference from NPs, present in the cells, the supernatant was transferred into clear 96well plates and absorbance measured at $570 \mathrm{~nm}$ with a microplate reader (Tecan, Männedorf, Switzerland). Cell viability (\%) was calculated based on the optical density of vehicle control and blank.

\section{Treatment of KeratinoSens ${ }^{\mathrm{TM}}$ Cells with Solubilized and Chelated Copper and Cobalt lons}

To evaluate the role of dissolved metal ions in cytotoxicity and sensitization, KeratinoSens ${ }^{\mathrm{TM}}$ cells were treated with solubilized metal ions followed by chelation, as described in our previous study, with slight modification (Jeong et al., 2018). Briefly, the stock solution of copper and cobalt chlorides in DW were incubated with Chelex 100 beads (Sigma-Aldrich) twice at 1:10 ratio $(\mathrm{v} / \mathrm{v})$ and shaken for $8 \mathrm{~h}$ at room temperature $\left(26 \pm 2^{\circ} \mathrm{C}\right)$. The beads were then removed by centrifugation at $15,000 \times \mathrm{g}$ for $30 \mathrm{~min}$. The collected supernatant was diluted to the working concentration $(2 \mathrm{mM})$ with cell culture medium and applied to KeratinoSens $^{\mathrm{TM}}$ cells.

\section{In Vivo Skin Sensitization Assay: LLNA-FCM}

Female BALB/C mice (7 weeks old, specific pathogen free) were purchased from ORIENT BIO Inc (Korea) and acclimated for at least 7 days before the experiments. The animals were kept at an animal facility in the Korea Ministry of Food and Drug Safety (MFDS). They were housed at a temperature of $22 \pm 3^{\circ} \mathrm{C}$ and relative humidity of $30-70 \%$. The study was approved by the Institutional Animal Care and Use Committee (IACUC) (2018, Approval NO. MFDS-18-145). On day 1, 2, and 3, $25 \mu \mathrm{L}$ of the dispersed NP suspension, vehicle, and positive control (25\% hexyl cinnamic aldehyde in AOO) were applied to the dorsal skin of each ear at the same time-point. Briefly, the NP stock solution was dispersed in DW at a concentration and sonicated at $40 \mathrm{kHz}$ with $100 \mathrm{~W}$ output power for $10 \mathrm{~min}$ in a bath-type sonicator (SaehanSonic). After dispersing the nanoparticle stock solution, 3\% mouse serum was used as a dispersant and sonicated for $10 \mathrm{~min}$ to increase the dispersion efficiency. Then the DMF solution was added at different working concentrations (Low dose: 25, Mid dose: 50, and High dose: 100 \%) for each NPs. NP suspensions were prepared fresh daily before application. On day 5 , the mice were intraperitoneally injected with $100 \mu \mathrm{L}$ of BrdU solution $(20 \mathrm{mg} / \mathrm{ml})$. On day 6 , all mice were sacrificed, and their auricular lymph nodes excised. The latter were then mashed with a spatula to prepare lymph node cells (LNCs). Isolated LNCs were counted using a hemocytometer after staining with trypan blue. The counted LNCs $\left(1.5 \times 10^{6}\right.$ cells $\left./ \mathrm{mL}\right)$ were prepared according to the protocol provided in the kit. Thereafter, viable LNCs were counted and 10,000 gated cells were analyzed using BD FACS Calibur ${ }^{\mathrm{TM}}$ flow cytometry (BD Biosciences), as described (Jung et al., 2010; Ahn et al., 2016). Stimulation index (SI) values were calculated using the formula described in OECD test guideline $442 \mathrm{~B}$ guideline. If the SI values were 2.7 or above, the test substance was classified as sensitizers.

\section{Histological Procedures for Mouse Ear Tissue Treated with NPs}

Mouse ear tissue was fixed with $10 \%$ neutral buffed formalin for $24 \mathrm{~h}$, followed by routine histological procedures. The tissue was stained lightly with eosin, which provided contrast from the metal oxide NPs. The NP aggregates in ear tissue were visualized by optical microscopy (Leica, Germany).

\section{Comparison Between the Component lons of Highly Soluble NPs by LLNA-FCM Assay} Constituent element ions were calculated from the concentrations of $\mathrm{CoO}$ and $\mathrm{CuO}$ (which are fast-dissolving NPs), as done previously, to prepare a suspension of constituent ions using corresponding metal chlorides. The concentrations of $\mathrm{CoCl}_{2}, \mathrm{CuCl}_{2}$, metal chlorides, used were the same ion molar concentration as the three concentrations of $\mathrm{CoO}$ and $\mathrm{CuO}$ nanoparticles tested previously (25, 50 and $100 \%)$. The LLNA-FCM assay was performed by treating animals via the same procedure as the described test method for NPs.

\section{Statistical Analysis}

Data of in vitro assay are expressed as mean \pm SD $(n=6)$. LLNA: BrdU-FCM data are expressed as mean \pm SD $(n=4)$. Statistical analysis was performed via one-way analysis of variance (ANOVA). Post hoc Tukey's pairwise comparison was performed for comparing between groups. Results were prepared using GraphPad Prism ver.7.0 (GraphPad Software, San Diego, CA). A $p$ value less than 0.05 was considered statistically significant.

\section{RESULTS}

\section{Physicochemical Properties of the Metal Oxide NPs}

Transmission electron microscopy images of the five metal oxide NPs used in this study are shown in Figure 1. Average sizes of the different NPs were $<100 \mathrm{~nm}$, like that of NPs provided by 

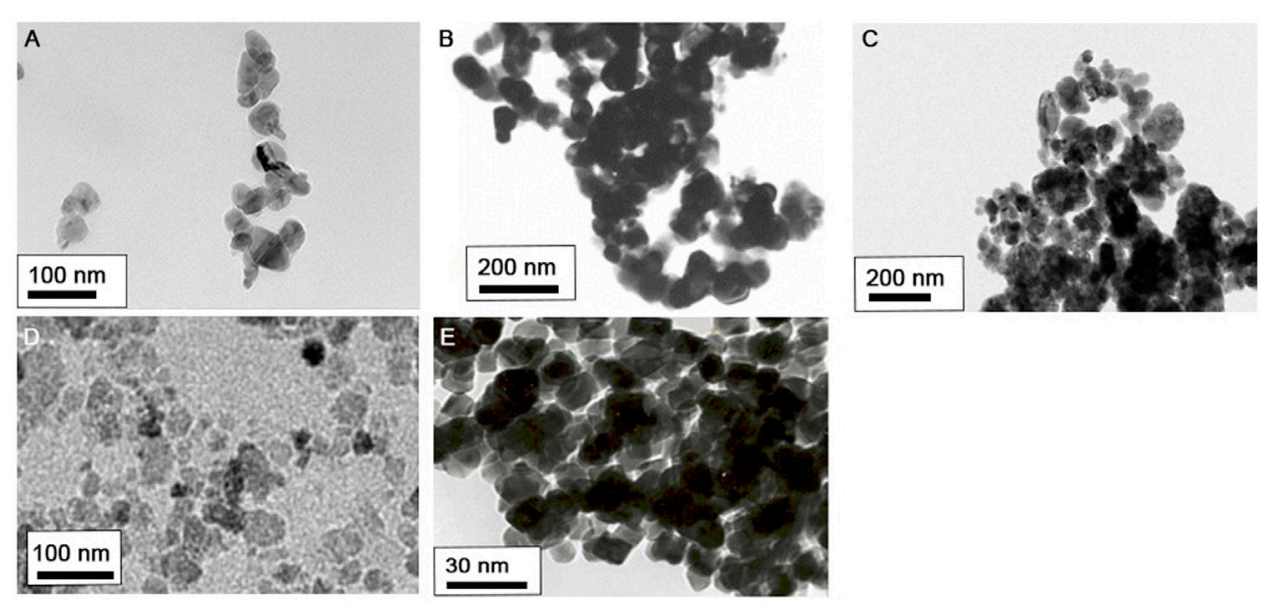

FIGURE 1 | Morphology of five metal oxide NPs observed by transmission electron microscopy (TEM): (A) $\mathrm{CoO},(\mathbf{B}) \mathrm{CO}_{3} \mathrm{O}_{4},(\mathbf{C}) \mathrm{CuO}$, (D) $\mathrm{NiO}_{\text {, and }}$ (E) TiO 2 NPs.

\begin{tabular}{|c|c|c|c|c|c|}
\hline NPs & $\mathrm{CoO}$ & $\mathrm{Co}_{3} \mathrm{O}_{4}$ & CuO & $\mathrm{NiO}$ & $\mathrm{TiO}_{2}$ \\
\hline Primary size (nm) & $43.60 \pm 7.94$ & $41.12 \pm 12.06$ & $47.80 \pm 13.24$ & $19.10 \pm 5.97$ & $12.81 \pm 2.70$ \\
\hline \multicolumn{6}{|l|}{ Hydrodynamic size $(d, n m)$ in } \\
\hline DW & $251.8 \pm 6.1$ & $294.2 \pm 37.2$ & $261.3 \pm 11.1$ & $303.5 \pm 12.0$ & $491.2 \pm 73.8$ \\
\hline working solution (DMEM) ${ }^{\mathrm{a}}$ & $403.3 \pm 11.1$ & $336.8 \pm 45.3$ & $307.1 \pm 19.3$ & $276.6 \pm 62.1$ & $486.0 \pm 14.7$ \\
\hline working solution (DMF) & $492.9 \pm 13.3$ & $499.7 \pm 74.4$ & $349.9 \pm 7.2$ & $490.9 \pm 37.1$ & $793.8 \pm 63.3$ \\
\hline \multicolumn{6}{|l|}{ Polydispersity (PDI) in } \\
\hline DW & $0.45 \pm 0.07$ & $0.44 \pm 0.16$ & $0.18 \pm 0.07$ & $0.32 \pm 0.05$ & $0.52 \pm 0.28$ \\
\hline working solution (DMEM) ${ }^{\mathrm{a}}$ & $0.32 \pm 0.04$ & $0.53 \pm 0.12$ & $0.36 \pm 0.05$ & $0.50 \pm 0.11$ & $0.53 \pm 0.07$ \\
\hline working solution $(\mathrm{DMF})^{\mathrm{b}}$ & $0.39 \pm 0.06$ & $0.61 \pm 0.19$ & $0.30 \pm 0.10$ & $0.42 \pm 0.10$ & $0.31 \pm 0.03$ \\
\hline \multicolumn{6}{|l|}{ Zeta potential $(\mathrm{mV})$ in } \\
\hline DW & $17.38 \pm 0.55$ & $22.77 \pm 4.19$ & $15.33 \pm 2.17$ & $33.22 \pm 1.80$ & $13.43 \pm 0.31$ \\
\hline working solution (DMEM) ${ }^{\mathrm{a}}$ & $-26.42 \pm 1.10$ & $-28.70 \pm 1.13$ & $-28.00 \pm 1.20$ & $-23.50 \pm 1.87$ & $-24.60 \pm 1.19$ \\
\hline working solution (DMF) ${ }^{\mathrm{b}}$ & $-18.22 \pm 0.46$ & $-33.50 \pm 1.59$ & $-26.48 \pm 0.57$ & $-32.86 \pm 0.90$ & $-34.10 \pm 1.00$ \\
\hline \multicolumn{6}{|l|}{ Solubility (\%) in } \\
\hline ALF (pH 5.5) & 77.7 & 0.2 & 88.4 & 2.0 & 0.3 \\
\hline PBS (pH 7.4) & 5.4 & 0.1 & 0.1 & 1.8 & 0.2 \\
\hline Molecular weight (g/mol) & 74.93 & 240.8 & 79.5 & 74.7 & 79.6 \\
\hline Purity (\%) & 99.5 & 100 & 100 & 99 & 99.7 \\
\hline Endotoxin (U/mL) & $<0.1$ & $<0.1$ & $<0.1$ & $<0.1$ & $<0.1$ \\
\hline
\end{tabular}

$D W$, distilled water; ALF, artificial lysosomal fluid; PBS, phosphate-buffered saline. Data were expressed as mean $\pm S D$ from six independent experiments. ${ }^{a} D W$ stock (1\%) + DMEM containing $1 \%$ FBS, condition.

${ }^{b} \mathrm{DW}$ stock (10\%) + DMF containing $3 \%$ inactivated mice serum, condition.

manufacturers. Physicochemical properties of the five metal oxide NPs are summarized in Table 1. Hydrodynamic size analysis revealed them all to be agglomerated, based on their primary size (nm). Measurement of zeta potential showed all NPs to be positively charged in DW and negatively charged in DMEM, with zeta potentials of -23 to $-32 \mathrm{mV}$. The Limulus Amebocyte Lysate test showed all metal oxide NPs to have endotoxin levels lower than the limit of detection $(0.1 \mathrm{U} / \mathrm{mL})$. The dissolution test showed incubation of $\mathrm{CoO}$ and $\mathrm{CuO}$ NPs in artificial lysosomal fluid ( $\mathrm{pH}$ 5.5) for $48 \mathrm{~h}$ to result in dissolution of over $77.7 \%$, whereas $\mathrm{Co}_{3} \mathrm{O}_{4}, \mathrm{NiO}$, and $\mathrm{TiO}_{2}$ NPs had dissolution of $0.2,2.0$, and $0.3 \%$, respectively. However, all NPs dispersed in PBS showed less than $5.4 \%$ dissolution.

\section{Evaluation of NPs-Induced Sensitization in the KeratinoSens ${ }^{\mathrm{TM}}$ Assay}

The five metal oxide NPs were assessed for their skin sensitization potential using the KeratinoSens ${ }^{\mathrm{TM}}$ assay; the data are shown in Table 2 and Figure 2. CuO and CoO NPsinduced activity of the luciferase reporter by over 1.5-fold, suggesting their ability to cause skin sensitization. The other NPs did not increase luciferase activity in the KeratinoSens ${ }^{\mathrm{TM}}$ assay. The $\mathrm{EC}_{1.5}$ value for $\mathrm{CuO}$ and $\mathrm{CoO}$ NPs was 1.38 and $316.57 \mu \mathrm{M}$ respectively, classifying them as sensitizers, whereas the values were $>1,000 \mu \mathrm{M}$ for the remaining NPs, classifying them as non-sensitizers. 
TABLE 2 | KeratinoSens ${ }^{\mathrm{TM}}$ assay results with the five metal oxide NPs.

\begin{tabular}{|c|c|c|c|c|c|c|c|}
\hline \multirow[t]{2}{*}{ NPs } & \multirow[t]{2}{*}{ CAS RN } & \multirow[t]{2}{*}{ Physical form } & \multicolumn{5}{|c|}{ KeratinoSens $^{\mathrm{TM}}$ assay results } \\
\hline & & & Imax & $E C_{1.5}(\mu \mathrm{M})$ & Cell viability $(\%)^{a}$ & $\mathrm{IC}_{50}(\mu \mathrm{M})$ & Classification \\
\hline $\mathrm{CoO}$ & 1307-96-6 & Solid & 17.32 & 316.57 & $>70$ & 841.19 & Positive \\
\hline $\mathrm{Co}_{3} \mathrm{O}_{4}$ & 1308-06-1 & Solid & 1.07 & & $>70$ & $>2000$ & Negative \\
\hline $\mathrm{CuO}$ & 1317-38-0 & Solid & 6.70 & 1.38 & $>70$ & 122.74 & Positive \\
\hline $\mathrm{NiO}$ & 1313-99-1 & Solid & 1.05 & & $>70$ & $>2000$ & Negative \\
\hline $\mathrm{TiO}_{2}$ & 13463-67-7 & Solid & 1.30 & & $>70$ & $>2000$ & Negative \\
\hline
\end{tabular}

${ }^{a}$ Cell viability (\%) at $E C_{1.5}$.

A

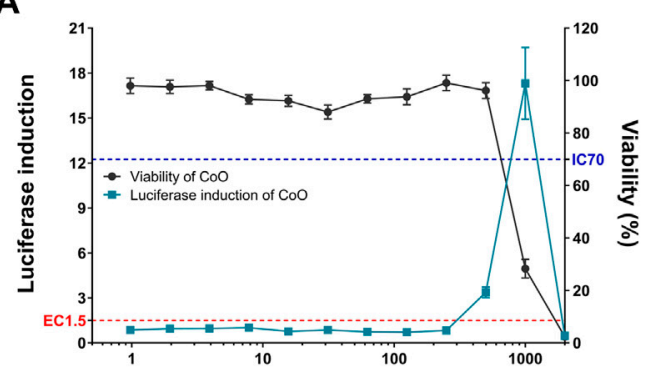

C

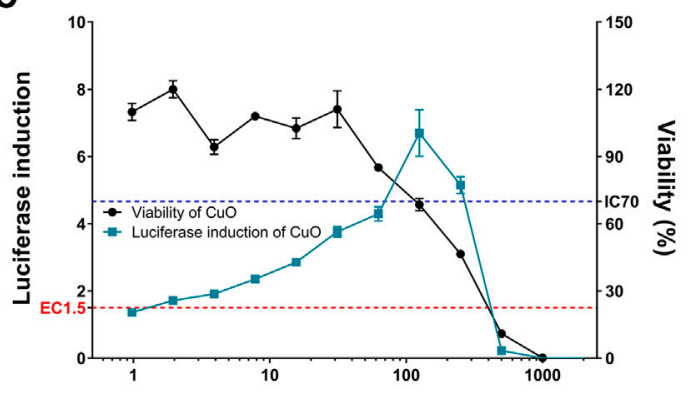

E

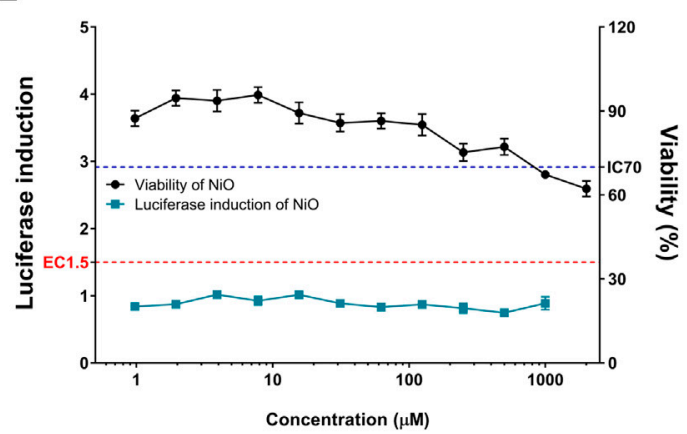

B

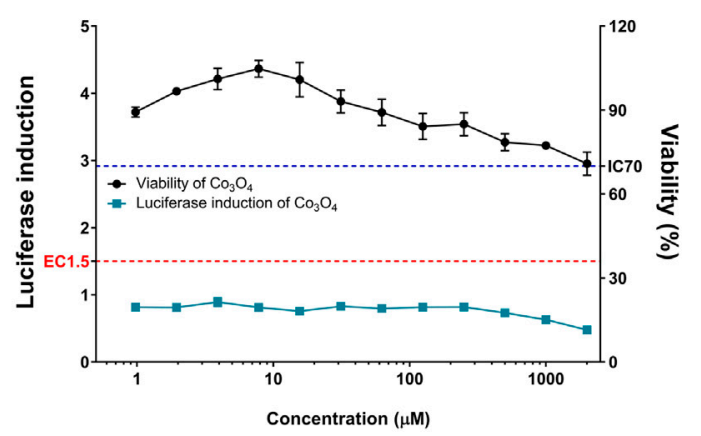

D

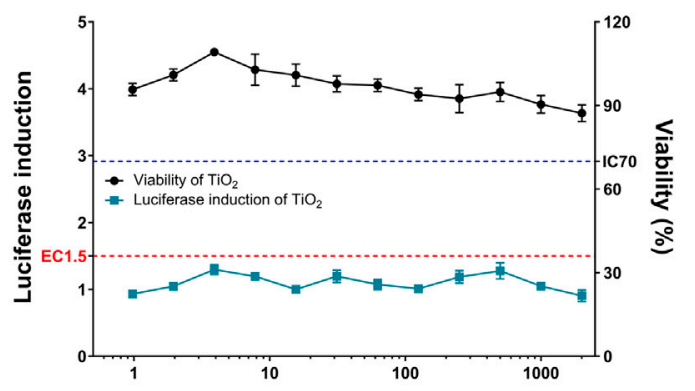

$\mathbf{F}$

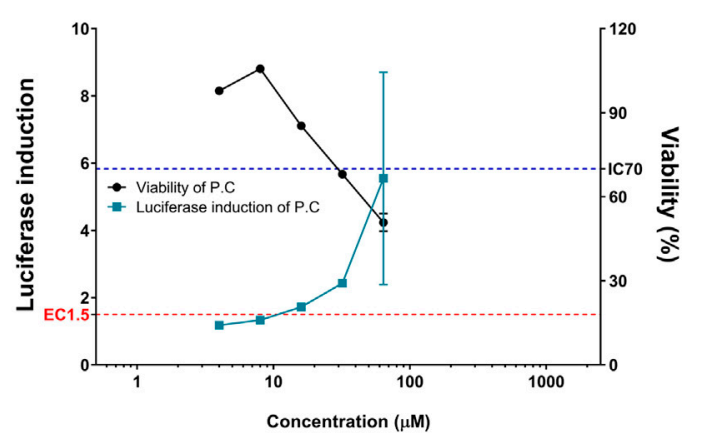

FIGURE 2 | Induction of luciferase activity (green squares) and cell viability (black rounds) in the KeratinoSens ${ }^{\mathrm{TM}}$ assay. KeratinoSens ${ }^{\mathrm{TM}}$ cells were treated with five metal oxide NPs: (A) $\mathrm{CoO}$, (B) $\mathrm{Co}_{3} \mathrm{O}_{4}$, (C) $\mathrm{CuO}$, (D) NiO, and (E) $\mathrm{TiO}_{2} \mathrm{NPs}$. (F) Positive control (cinnamic aldehyde, 4-64 $\mu \mathrm{M}$ ) was tested in parallel. Data are expressed as mean \pm standard deviation values $(n=6)$.

Comparison Between Highly Soluble Metal Oxide (CoO and CuO) NPs and Corresponding Metal lons

$\mathrm{CoO}$ and $\mathrm{CuO}$ NPs were selected based on elemental analysis (ICP-OES) data for studying the effect of NPs with fast-dissolving ability and comparison of the same with corresponding metal ions. Cytotoxicity and luciferase induction in KeratinoSens ${ }^{\mathrm{TM}}$ cells were measured using $\mathrm{CoCl}_{2}$ and $\mathrm{CuCl}_{2}$, which are ionic forms of the nanoparticles (Figure 3). Results of the ion-dose treatment of Cobalt and Copper metal chlorides and treatment of $\mathrm{CoO}$ and $\mathrm{CuO}$ NPs showed similar dose-dependent features in the two analyses. 

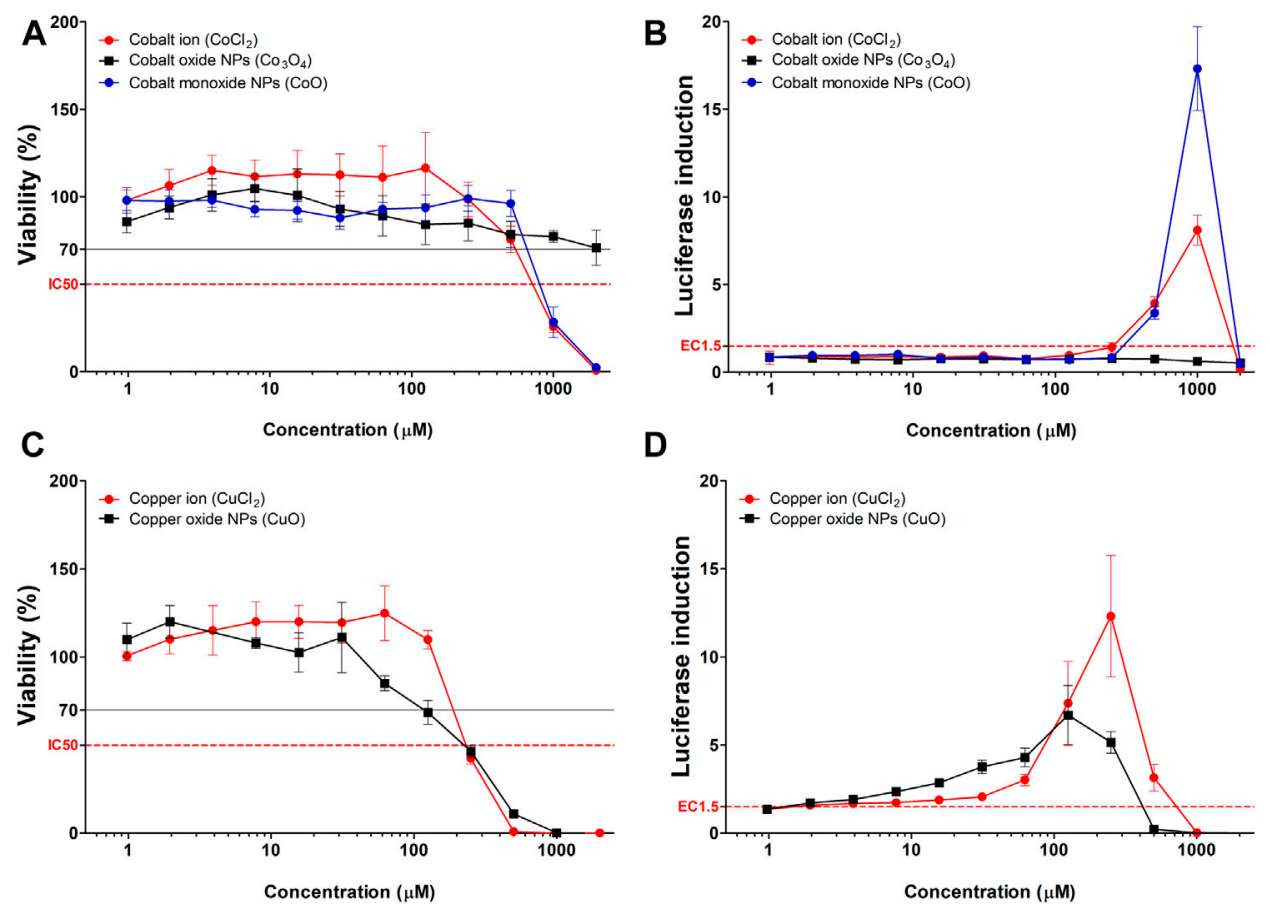

FIGURE 3 | Comparison of luciferase induction assay results between highly soluble metal oxide NPs and their component metal ions. (A) Viability and (B) luciferase induction $\mathrm{CoO}, \mathrm{Co}_{3} \mathrm{O}_{4} \mathrm{NPs}$, and $\mathrm{CoCl}_{2}$. (C) Viability and (D) luciferase induction $\mathrm{CuO}$ NPs and $\mathrm{CuCl}_{2}$. Data are expressed as mean \pm standard deviation values $(\mathrm{n}=6$ ).
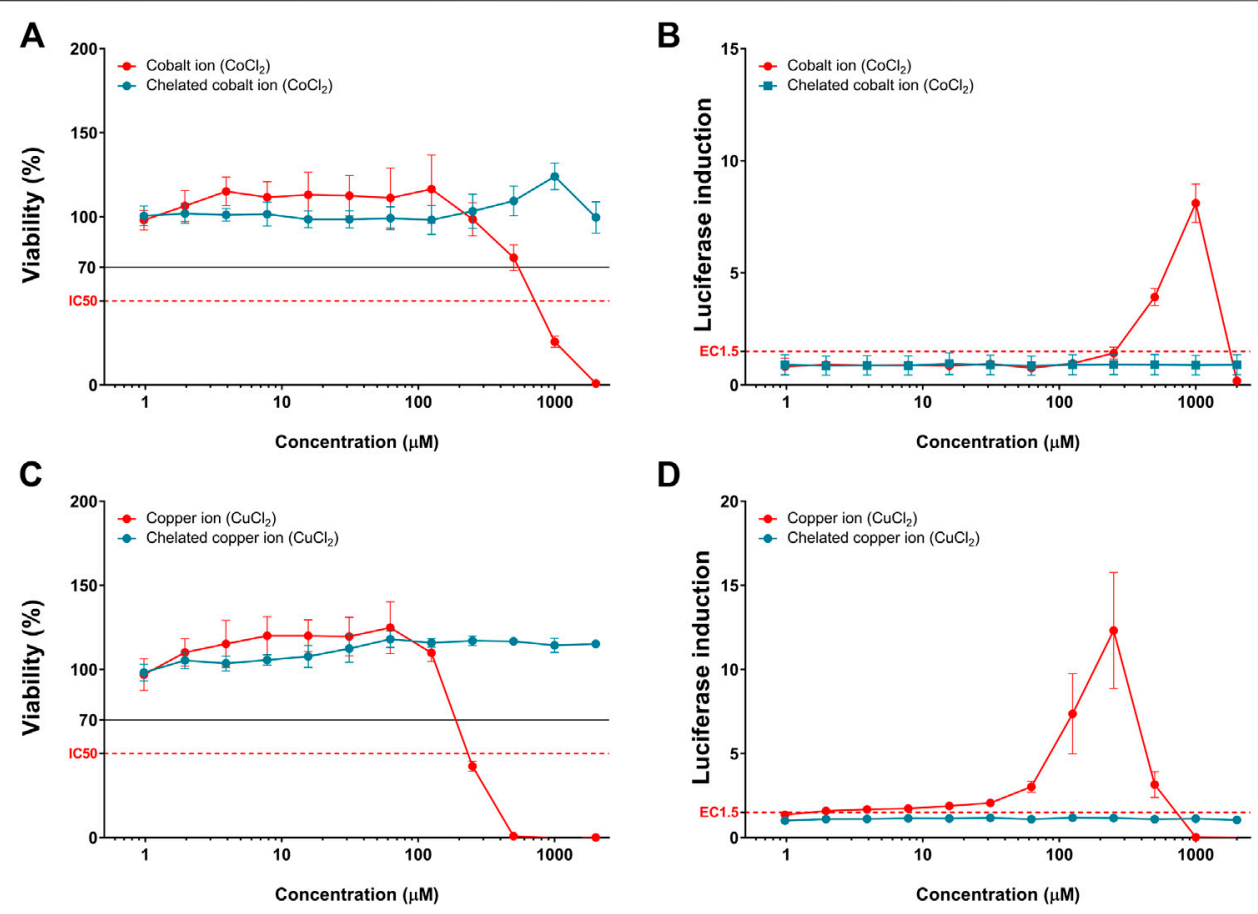

D

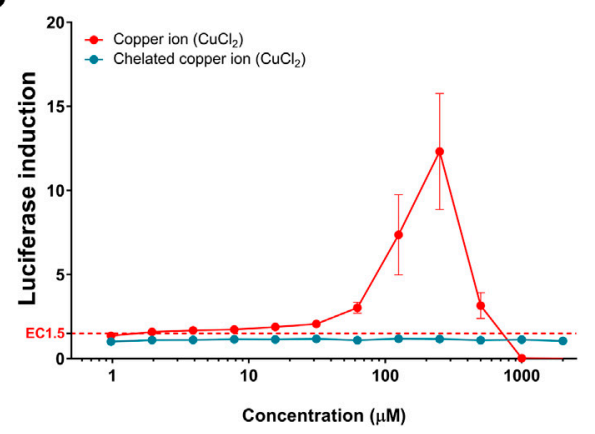

FIGURE 4 | Comparison of luciferase induction and cytotoxicity results between the chelated and non-chelated metal chlorides. (A) Viability and (B) luciferase induction of cobalt chloride $\left(\mathrm{CoCl}_{2}\right)$. (C) Viability and (D) luciferase induction of copper chloride $\left(\mathrm{CuCl}_{2}\right)$. Data are expressed as mean \pm standard deviation values $(\mathrm{n}=6)$. 

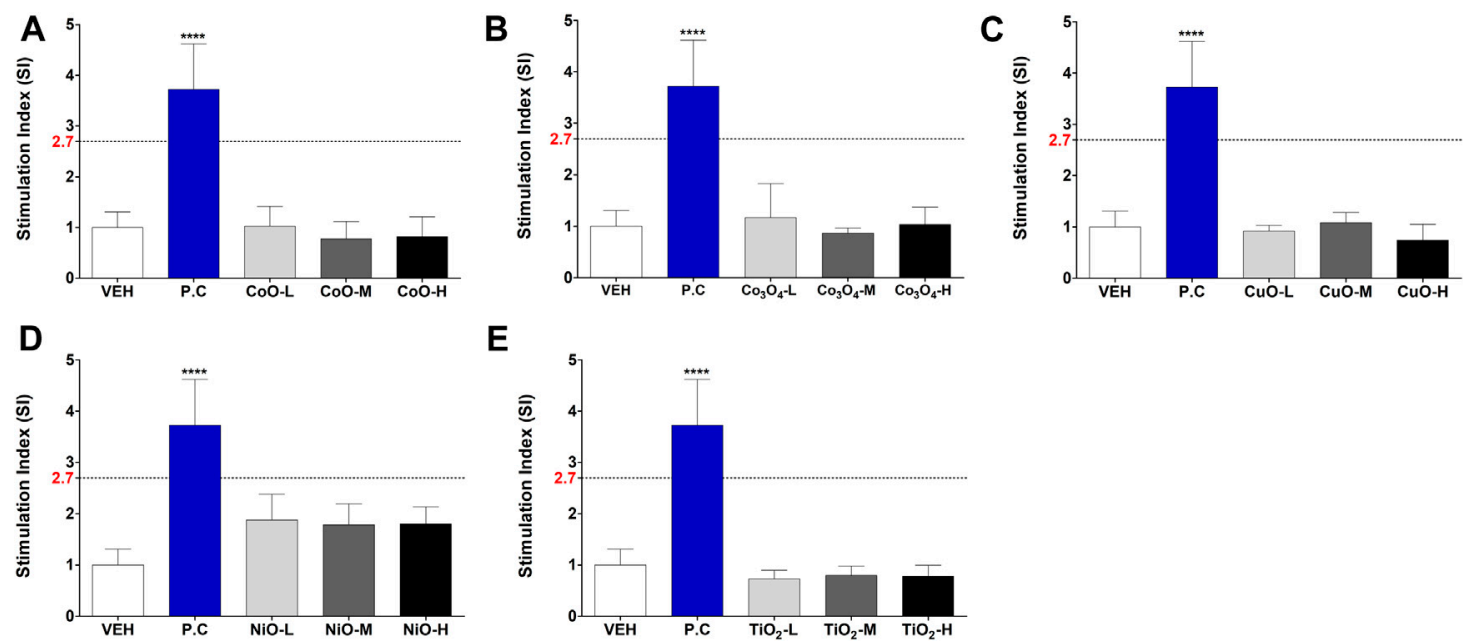

FIGURE 5 | Induction of stimulation index (SI) in the LLNA: BrdU-FCM assay. Animals were administered five metal oxide NPs: (A) $\mathrm{CoO}$, (B) $\mathrm{Co}_{3} \mathrm{O}_{4}$, (C) $\mathrm{CuO}$, (D) $\mathrm{NiO}$, and (E) $\mathrm{TiO}_{2} \mathrm{NPs}$. Data are expressed as mean \pm standard deviation values $(\mathrm{n}=4)$. Significance vs. vehicle control: ${ }^{\star \star \star \star} p<0.0001$
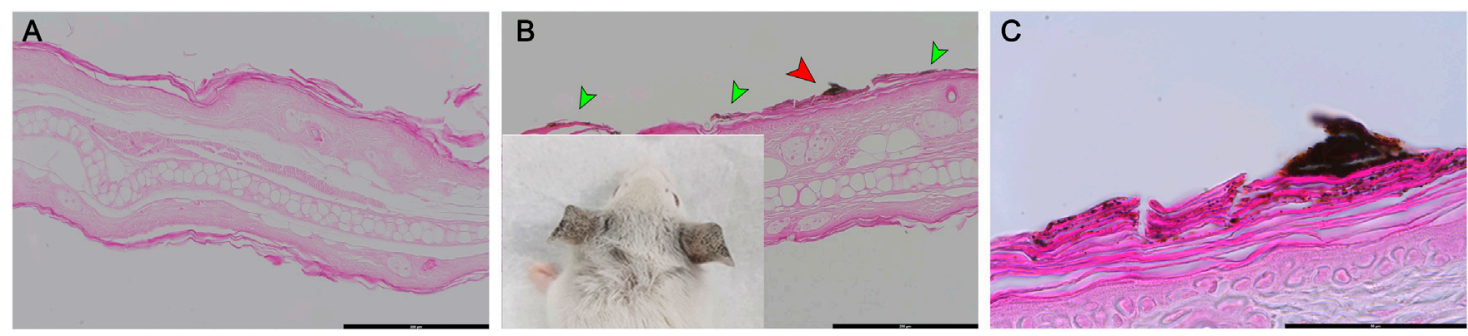

FIGURE 6 | Histologic examination of eosin-stained ear skin tissue after exposure of mice to copper oxide NPs. (A) Vehicle control (DMF), (B) and (C) treated with CuO NPs. CuO NPs accumulated in the stratum corneum (green arrow). (C) is a high-magnification image of the red arrow portion in (B). Scale bars: (A) $200 \mu \mathrm{m}$, (B) $200 \mu \mathrm{m}$, (C) $50 \mu \mathrm{m}$.

\section{Differential Luciferase Induction After Chelation of Metal Chlorides}

The chelation of copper and cobalt chlorides showed dramatic recovery of cytotoxicity, along with non-sensitization results, compared to that with non-chelated metal chlorides (Figure 4). Although metal chlorides showed significant luciferase induction and cytotoxicity in KeratinoSens ${ }^{\text {TM }}$ cells, chelation of metals showed no fold induction and cytotoxicity at the doses tested.

\section{Evaluation of the Five Metal Oxide NPs Using LLNA-FCM Assay}

Metal oxide NPs were assessed for their skin sensitization potential using the LLNA: BrdU-FCM assay, data shown in Figure 5. The SI was obtained by flow cytometry, and for all metal oxide NPs, SI value was less than 2.7.

\section{Observation of CuO NP Aggregates in the Stratum Corneum}

To visualize the NPs penetration, mouse ear tissues were stained lightly with eosin, which provided contrast from the dark NPs (Figure 6). $\mathrm{CuO} \mathrm{NP}$-exposed mouse ear showed large aggregates in the stratum corneum (Figures 6B,C). Upon measurement of the approximate size of the particles, agglomerates of nanoparticles $400-1,000 \mathrm{~nm}$ were observed.

\section{Differential Skin Sensitization Potential of NPs and Component Metal lons per LLAN:-BrdU-FCM Assay}

The SI results of NPs and metal chlorides are presented in Figure 7. SI value of the metal oxide NPs was less than 2.7. $\mathrm{CoCl}_{2}$ and $\mathrm{CuCl}_{2}$ metal chlorides showed higher SI value than metal oxide ( $\mathrm{CoO}$ and $\mathrm{CuO}) \mathrm{NPs}$, respectively. 

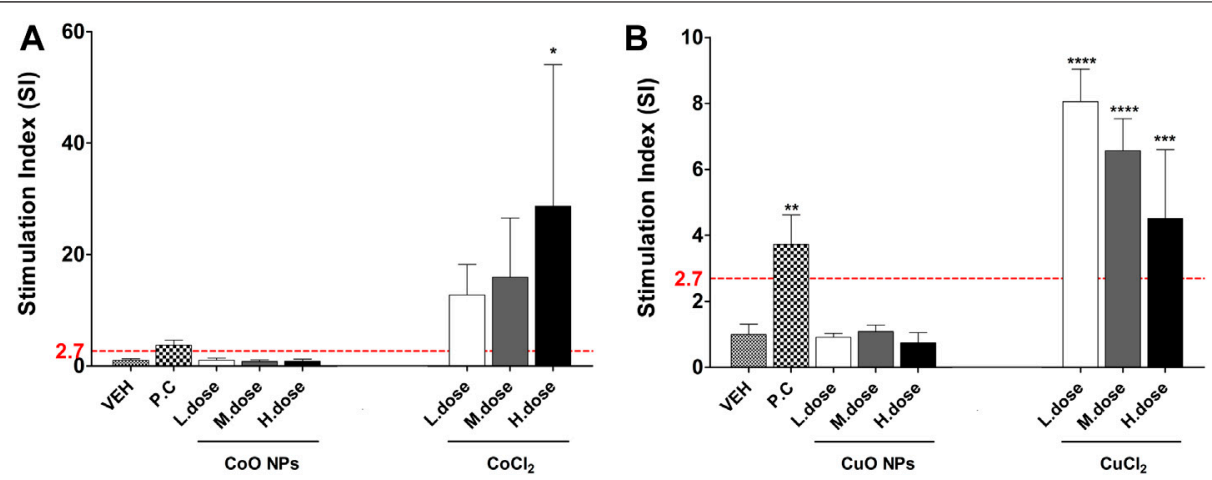

FIGURE 7 | The SI value in LLNA-FCM assay due to metal oxide NPs and component metal ions (Cobalt and copper). Animals were treated with: (A) Cobaltcontaining compound, and (B) Copper-containing compound. Data are expressed as mean \pm standard deviation values $(\mathrm{n}=4)$. Significance vs. vehicle control: ${ }^{\star \star \star \star} p<0.0001$

\section{DISCUSSION}

This study was conducted to evaluate the skin sensitization potential of metal oxide NPs using the ARE-Nrf2 Luciferase KeratinoSens $^{\mathrm{TM}}$ assay and LLNA: BrdU-FCM assay. These assays were based on the second and fourth key events of skin sensitization; it evaluated whether a test substance sensitizes skin at the keratinocyte or in vivo levels (OECD, 2018a; OECD, 2018b). We had previously confirmed the applicability of this method using metal oxide nanoparticles, and this study investigated the effect of dissolution of metal nanomaterials on skin sensitization (Kim et al., 2020).

The level of reproducibility of the predictions expected from the KeratinoSens ${ }^{\mathrm{TM}}$ assay was approximately $85 \%$ within and across laboratories. The accuracy of identifying a skin sensitizer by this test method has been demonstrated to be $77 \%(155 / 201)$, with a sensitivity of $78 \%$ (71/91) (Natsch et al., 2013; EURLECVAM, 2014). Collectively, available data indicated the KeratinoSens $^{\mathrm{TM}}$ assay to be useful for identifying the risk of skin sensitization by various compounds (Emter et al., 2010; Andreas et al., 2011; EURL-ECVAM, 2014). After 145 chemical tests, the KeratinoSens ${ }^{\mathrm{TM}}$ assay was recognized as an OECD guideline and is being evaluated as an alternative test guideline (Natsch et al., 2013). Skin sensitization tests are performed using purified chemicals; however, evaluation of materials that are not completely dissolved has also been reported (Andres et al., 2013; Settivari et al., 2015).

LLNA: BrdU-FCM assay was developed to replace the traditional radioisotopic LLNA; it could reduce the pain inflicted on animals, since it did not use immunoadjuvants and required a lesser number of animals for the test (OECD, 2018b). Skin sensitization study of some NPs such as $\mathrm{TiO}_{2}$ and $\mathrm{ZnO}$ had been performed previously using LLNA assay (Park et al., 2011; Jang et al., 2012); these were determined to be nonsensitizers.
To accurately identify the toxicity of nanomaterials, it would be important to produce a stable and uniform dispersion, since nanomaterial aggregates may exert different biological effects compared to well-dispersed nanomaterials (Bihari et al., 2008). The NPs show large aggregation when preparing suspensions with ordinary vehicle solutions in LLNA: BrdU-FCM assays. According to Bihari et al., 2008; Lee et al., 2016, the use of inactivated serum of the same species/strain as a dispersant could contribute to the reduction of hydrodynamic size (reduction of aggregation) in the NPs suspension.

In our study, the same substance was evaluated using the two test methods. It was found that $\mathrm{TiO}_{2} \mathrm{NP}$ does not exhibit skin sensitization when evaluated using skin sensitization assay. Nickel is known as a positive sensitizer in humans and as per GMPT test results. However, as a limitation, nickel is shown as 'false negative' in the alternative test method (Williams et al., 2015). In the KeratinoSens ${ }^{\mathrm{TM}}$ assay, $\mathrm{CoO}$ and $\mathrm{CuO}$ NPs were positive sensitizers while they were negative in in vivo results. Copper and cobalt are reported as sensitizing substances (Wang et al., 2018); however, in this study, the two test methods showed contradictory results.

Factors such as "very small," "skin injury," or "solubility of the materials" can promote the penetration of the substance into the skin. Skin penetration is possible at sizes below $20 \mathrm{~nm}$, but nanomaterials are known to have low skin penetration (Filon et al., 2015; Yoshioka et al., 2017). When a sensitizing substance does not pass through the skin, accurate test results may not be obtained. In this study, it was confirmed that nanomaterials form large aggregates in the stratum corneum of the ear tissue. In addition, since the size of the nanomaterials of the working fluid used in the in vivo test is $300 \sim 500 \mathrm{~nm}$ or more, it is considered that it could not have penetrated the skin.

We estimated that the difference in the in vivo and in vitro results of $\mathrm{CuO}$ and $\mathrm{CoO}$ NPs was due to their ability to 
generate metal ions. $\mathrm{CuO}$ and $\mathrm{CoO}$ NPs used in this test are reported to exhibit high solubility in the intracellular environment (Jeong et al., 2018). These highly ionized NPs rapidly dissolve in the lysosome and are released like a "Trojan horse," causing cytotoxicity. The results of the metal ions treated with the same ion concentration as the $\mathrm{CoO}$ and $\mathrm{CuO}$ NPs showed a remarkably similar concentration-dependent pattern in the KeratinoSens ${ }^{\mathrm{TM}}$ assay. When looking at the results of $\mathrm{Co}_{3} \mathrm{O}_{4} \mathrm{NPs}$, which has the same element as cobalt but does not dissolve well, CoO NPs showed more similarity with cobalt ions. In addition, the chelation test results of metal ions proved that the removal of metal ions does not induce sensitization. Therefore, the result obtained through this study is that the dissolution of metal NMs had an important effect on inducing skin sensitization. Our study investigated the potential of skin sensitization for five metal oxide NPs. Since only a few of the various NMs have been evaluated, more studies are needed to elucidate the mechanism of in-depth skin sensitization by NMs.

\section{CONCLUSION}

In this study, evaluation of skin sensitization by NPs, through two skin sensitization test methods, showed the sensitization potential of $\mathrm{CuO}$ and $\mathrm{CoO}$ NPs. The effect was induced by the constituent elements of fast-dissolving NPs. Based on ion chelation data; metal ion release was confirmed as the major "factor" for skin sensitization. If the NPs are to be applied to alternative test methods or investigating skin sensitization, their physicochemical properties, including dissolution of NPs, would need to be considered. However, further investigations would be required to elucidate the mechanism underlying NPsinduced skin sensitization.

\section{REFERENCES}

Ahn, I., Kim, T. S., Jung, E. S., Yi, J. S., Jang, W. H., Jung, K. M., et al. (2016). Performance standard-based validation study for local lymph node assay: 5bromo-2-deoxyuridine-flow cytometry method. Regul. Toxicol. Pharmacol. 80, 183-194. doi:10.1016/j.yrtph.2016.06.009

Andreas, N., Caroline, B., Leslie, F., Frank, G., Kimberly, N., Allison, H., et al. (2011). The intra- and inter-laboratory reproducibility and predictivity of the KeratinoSens assay to predict skin sensitizers in vitro: results of a ring-study in five laboratories. Toxicol. In Vitro 25, 733-744. doi:10.1016/j.tiv.2010.12.014

Andres, E., Sá-Rocha, V. M., Barrichello, C., Haupt, T., Ellis, G., and Natsch, A. (2013). The sensitivity of the KeratinoSens ${ }^{\mathrm{TM}}$ assay to evaluate plant extracts: a pilot study. Toxicol. In Vitro 27, 1220-1225. doi:10.1016/j.tiv.2013.02.008

Bihari, P., Vippola, M., Schultes, S., Praetner, M., Khandoga, A. G., Reichel, C. A., et al. (2008). Optimized dispersion of nanoparticles for biological in vitro and in vivo studies. Part. Fibre Toxicol. 5, 14. doi:10.1186/1743-8977-5-14

Braakhuis, H. M., Park, M. V., Gosens, I., De Jong, W. H., and Cassee, F. R. (2014). Physicochemical characteristics of nanomaterials that affect pulmonary inflammation. Part. Fibre Toxicol. 11, 18. doi:10.1186/17438977-11-18

Cho, W. S., Duffin, R., Thielbeer, F., Bradley, M., Megson, I. L., MacNee, W., et al. (2012). Zeta potential and solubility to toxic ions as mechanisms of lung inflammation caused by metal/metal oxide nanoparticles. Toxicol. Sci. 126, 469-477. doi:10.1093/toxsci/kfs006

\section{DATA AVAILABILITY STATEMENT}

The original contributions presented in the study are included in the article/Supplementary Material, further inquiries can be directed to the corresponding authors.

\section{ETHICS STATEMENT}

The study was approved by the Institutional Animal Care and Use Committee (IACUC) (2018, Approval No. MFDS-18-145) of the Ministry of Food and Drug Safety.

\section{AUTHOR CONTRIBUTIONS}

Participated in the experimental design and data analysis: S-HK, and JKL. Conducted the experiments: S-HK, JHL, and KJ with help of JL, J-YY, and H-SS. Contributed to the writing of the manuscript: S-HK, JJ, J-HO, and JK. All authors read and approved the final version of the manuscript.

\section{FUNDING}

This study was supported by the Ministry of Food and Drug Safety for 2018-2020 (grant numbers 18181MFDS361 and 20181MFDS401).

\section{ACKNOWLEDGMENTS}

We would like to thank Editage (www.editage.co.kr) for English language editing.

Cho, W. S., Kang, B. C., Lee, J. K., Jeong, J., Che, J. H., and Seok, S. H. (2013). Comparative absorption, distribution, and excretion of titanium dioxide and zinc oxide nanoparticles after repeated oral administration. Part. Fibre Toxicol. 10, 9. doi:10.1186/1743-8977-10-9

Donaldson, K., Schinwald, A., Murphy, F., Cho, W. S., Duffin, R., Tran, L., et al. (2013). The biologically effective dose in inhalation nanotoxicology. Acc. Chem. Res. 46, 723-732. doi:10.1021/ar300092y

Dwivedi, P. D., Tripathi, A., Ansari, K. M., Shanker, R., and Das, M. (2011). Impact of nanoparticles on the immune system. J. Biomed. Nanotechnol. 7, 193-194. doi:10.1166/jbn.2011.1264

Dykman, L. A., and Khlebtsov, N. G. (2017). Immunological properties of gold nanoparticles. Chem. Sci. 8, 1719-1735. doi:10.1039/c6sc03631g

Emter, R., Ellis, G., and Natsch, A. (2010). Performance of a novel keratinocytebased reporter cell line to screen skin sensitizers in vitro. Toxicol. Appl. Pharmacol. 245, 281-290. doi:10.1016/j.taap.2010.03.009

EURL-ECVAM (2014). Recommendation on the KeratinoSens ${ }^{\mathrm{TM}}$ assay for skin sensitisation testing. Available at: https:/ec.europa.eu/jrc/en/publication/ eur-scientific-and-technical-research-reports/eurl-ecvam-recommendationkeratinosenstm-assay-skin-sensitisation-testing (Accessed October 22, 2020).

Jang, Y. S., Lee, E. Y., Park, Y. H., Jeong, S. H., Lee, S. G., Kim, Y. R., et al. (2012). The potential for skin irritation, phototoxicity, and sensitisation of $\mathrm{ZnO}$ nanoparticles. Mol. Cell. Toxicol. 8, 171-177. doi:10.1007/s13273-012-0021-9

Jeong, J., Han, Y., Poland, C. A., and Cho, W. S. (2015). Response-metrics for acute lung inflammation pattern by cobalt-based nanoparticles. Part. Fibre Toxicol. 12 (1), 13. doi:10.1186/s12989-015-0089-1 
Jeong, J., Kim, S. H., Lee, S., Lee, D. K., Han, Y., Jeon, S., et al. (2018). Differential contribution of constituent metal ions to the cytotoxic effects of fast-dissolving metal-oxide nanoparticles. Front. Pharmacol. 9, 15. doi:10.3389/fphar.2018. 00015

Jeong, J., Lee, S., Kim, S. H., Han, Y., Lee, D. K., Yang, J. Y., et al. (2016). Evaluation of the dose metric for acute lung inflammogenicity of fast-dissolving metal oxide nanoparticles. Nanotoxicology 10, 1448-1457. doi:10.1080/17435390. 2016.1229518

Jung, K. M., Bae, I. H., Kim, B. H., Kim, W. K., Chung, J. H., Park, Y. H., et al. (2010). Comparison of flow cytometry and immunohistochemistry in nonradioisotopic murine lymph node assay using bromodeoxyuridine. Toxicol. Lett. 192 (2), 229-237. doi:10.1016/j.toxlet.2009.10.024

Kaluzhny, Y., Kandárová, H., Hayden, P., Kubilus, J., d'Argembeau-Thornton, L., and Klausner, M. (2011). Development of the EpiOcular(TM) eye irritation test for hazard identification and labelling of eye irritating chemicals in response to the requirements of the EU cosmetics directive and REACH legislation. Altern. Lab Anim. 39 (4), 339-364. doi:10.1177/ 026119291103900409

Katz, L. M., Dewan, K., and Bronaugh, R. L. (2015). Nanotechnology in cosmetics. Food Chem. Toxicol. 85, 127-137. doi:10.1016/j.fct.2015.06.020

Kim, S. H., Lee, D. H., Lee, J. H., Yang, J. Y., Seok, J. H., Jung, K., et al. (Forthcoming 2020). Evaluation of the skin sensitization potential of metal oxide nanoparticles using the ARE-Nrf2 Luciferase KeratinoSens ${ }^{\mathrm{TM}}$ assay. Toxicol. Res. doi:10.1007/s43188-020-00071-0

Larese Filon, F., Mauro, M., Adami, G., Bovenzi, M., and Crosera, M. (2015). Nanoparticles skin absorption: new aspects for a safety profile evaluation. Regul. Toxicol. Pharmacol. 72 (2), 310-322. doi:10.1016/j.yrtph.2015.05.005

Lee, S., Hwang, S. H., Jeong, J., Han, Y., Kim, S. H., Lee, D. K., et al. (2016). Nickel oxide nanoparticles can recruit eosinophils in the lungs of rats by the direct release of intracellular eotaxin. Part. Fibre Toxicol. 13 (1), 30. doi:10.1186/ s12989-016-0142-8

Maynard, A. D., and Kuempel, E. D. (2005). Airborne nanostructured particles and occupational health. J. Nanoparticle Res. 7, 587-614. doi:10.1007/s11051-0056770-9

Natsch, A., Ryan, C. A., Foertsch, L., Emter, R., Jaworska, J., Gerberick, F., et al. (2013). A dataset on 145 chemicals tested in alternative assays for skin sensitization undergoing prevalidation. J. Appl. Toxicol. 33, 1337-1352. doi:10.1002/jat.2868

Oberdörster, G., Oberdörster, E., and Oberdörster, J. (2005). Nanotoxicology: an emerging discipline evolving from studies of ultrafine particles. Environ. Health Perspect. 113, 823-839. doi:10.1289/ehp.7339
OECD (2018a). Test No. 442D Vitro skin sensitisation: ARE-Nrf2 luciferase test method, OECD guidelines for the testing of chemicals, section 4. Paris, France: OECD Publishing. doi:10.1787/9789264229822-en

OECD (2018b). Test No. 442B: skin sensitization: local lymph node assay: BrdUELISA or-FCM, OECD guidelines for the testing of chemicals, section 4. Paris, France: OECD Publishing. doi:10.1787/9789264090996-en

OECD (2014). The adverse outcome pathway for skin sensitisation initiated by covalent binding to proteins, OECD series on testing and assessment 168. Paris, France: OECD Publishing. doi:10.1787/9789264221444-en

Park, Y. H., Jeong, S. H., Yi, S. M., Choi, B. H., Kim, Y. R., Kim, I. K., et al. (2011). Analysis for the potential of polystyrene and $\mathrm{TiO} 2$ nanoparticles to induce skin irritation, phototoxicity, and sensitization. Toxicol. In Vitro 25, 1863-1869. doi:10.1016/j.tiv.2011.05.022

Rusche, B. (2003). The 3 Rs and animal welfare - conflict or the way forward?. ALTEX 20 (1), 63-76.

Settivari, R. S., Gehen, S. C., Amado, R. A., Visconti, N. R., Boverhof, D. R., and Carney, E. W. (2015). Application of the KeratinoSens ${ }^{\mathrm{TM}}$ assay for assessing the skin sensitization potential of agrochemical active ingredients and formulations. Regul. Toxicol. Pharmacol. 72, 350-360. doi:10.1016/j.yrtph.2015.05.006

Wang, M., Lai, X., Shao, L., and Li, L. (2018). Evaluation of immunoresponses and cytotoxicity from skin exposure to metallic nanoparticles. Int. J. Nanomed. 13, 4445. doi:10.2147/IJN.S170745

Williams, W. C., Copeland, C., Boykin, E., Quell, S. J., and Lehmann, D. M. (2015). Development and utilization of an ex vivo bromodeoxyuridine local lymph node assay protocol for assessing potential chemical sensitizers. J. Appl. Toxicol. 35 (1), 29-40. doi:10.1002/jat.2983

Yoshioka, Y., Kuroda, E., Hirai, T., Tsutsumi, Y., and Ishii, K. J. (2017). Allergic responses induced by the immunomodulatory effects of nanomaterials upon skin exposure. Front. Immunol. 8, 169. doi:10.3389/fimmu.2017.00169

Conflict of Interest: The authors declare that the research was conducted in the absence of any commercial or financial relationships that could be construed as a potential conflict of interest.

Copyright (c) $2021 \mathrm{Kim}$, Lee, Jung, Yang, Shin, Lee, Jeong, Oh and Lee. This is an open-access article distributed under the terms of the Creative Commons Attribution License (CC BY). The use, distribution or reproduction in other forums is permitted, provided the original author(s) and the copyright owner(s) are credited and that the original publication in this journal is cited, in accordance with accepted academic practice. No use, distribution or reproduction is permitted which does not comply with these terms. 